\title{
Commentary: The aggregation of marginal gains for spinal cord protection
}

\author{
Subhasis Chatterjee, MD, ${ }^{\mathrm{a}, \mathrm{b}, \mathrm{c}}$ \\ Ourania Preventza, MD, ${ }^{\mathrm{b}, \mathrm{c}}$ and \\ Joseph S. Coselli, MD ${ }^{\mathrm{b}, \mathrm{c}}$
}

In the seminal report of E. Stanley Crawford's experience with 1509 patients with thoracoabdominal aortic aneurysm (TAAA) who underwent surgery from 1960 to 1991, the incidence of spinal cord injury (SCI) with paraplegia was $16 \%$ for all TAAA repairs and $31 \%$ for extent II TAAA repairs. ${ }^{1}$ Yet Crawford and colleagues persisted. After almost 4 decades and many advances in spinal cord protection, including left heart bypass, mild hypothermia, cerebrospinal fluid drainage (CSFD), and reimplantation of intercostal or lumbar arteries, the modern rate of permanent SCI now approaches $5 \%$ for TAAA repairs as a whole and $8 \%$ for extent II cases. ${ }^{2}$

Abdelbaky and colleagues ${ }^{3}$ illustrate the experience of Elefteriades and the Yale group in this issue of JTCVS Techniques. This report continues the group's valuable and long-standing contributions to our understanding of the management of thoracic aortic disease. The very good overall results the authors describe attest to the group's experience with this procedure. In this cohort of 100 patients (mean age, 65 years) with descending thoracic aneurysm $(\mathrm{DTA} ; \mathrm{n}=33)$ and TAAA $(\mathrm{n}=67)$ in which all patients

\footnotetext{
From the Divisions of ${ }^{\mathrm{a}}$ General Surgery and ${ }^{\mathrm{b}}$ Cardiothoracic Surgery, Michael E. DeBakey Department of Surgery, Baylor College Medicine; and ${ }^{\mathrm{c} D e p a r t m e n t}$ of Cardiovascular Surgery, Texas Heart Institute, Houston, Tex.

Disclosures: J.S.C. consults for and participates in clinical trials with Medtronic and W. L. Gore \& Associates, Inc; consults for, participates in clinical trials with, and receives royalties and grant support from Terumo Aortic; and serves as a coinvestigator for CytoSorbents. O.P. consults for and participates in clinical trials with Medtronic and W. L. Gore \& Associates, Inc. S.C. reported no conflicts of interest.

The Journal policy requires editors and reviewers to disclose conflicts of interest and to decline handling or reviewing manuscripts for which they may have a conflict of interest. The editors and reviewers of this article have no conflicts of interest.

Received for publication Dec 18, 2020; revisions received Dec 18, 2020; accepted for publication Dec 23, 2020; available ahead of print Dec 26, 2020.

Address for reprints: Subhasis Chatterjee, MD, Baylor College of Medicine, One Baylor Plaza, MS: BCM 390, Houston, TX 77030-3411 (E-mail: subhasis. chatterjee@bcm.edu).

JTCVS Techniques 2021;6:9-10

2666-2507

Copyright (C) 2021 The Authors. Published by Elsevier Inc. on behalf of The American Association for Thoracic Surgery. This is an open access article under the CC BY-NCND license (http://creativecommons.org/licenses/by-nc-nd/4.0/).

https://doi.org/10.1016/j.xjtc.2020.12.031
}

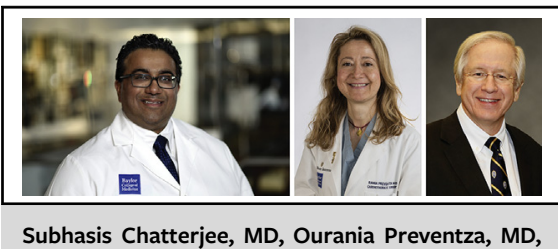

and Joseph S. Coselli, MD

CENTRAL MESSAGE

Spinal cord injury is a devastating complication of thoracoabdo-

minal aortic aneurysm repair. The use of cerebrospinal fluid drains

is an important adjunct for

reducing the risk of spinal cord

injury.

received CSFD, overall mortality was $6 \% ; 4 \%$ of patients had transient paraparesis, and $2 \%$ had permanent paraplegia. Most cases were elective ( $92 \%$ ), with the most common diagnoses being nondissected aneurysm $(55 \%)$ and chronic type B dissection (28\%).

Any meaningful evaluation of a TAAA series and associated SCI complications requires an apples-to-apples comparison. This entails recognizing the distribution of patients with TAAA versus those with DTA and the proportion of the various TAAA extents, with particular attention to extents II and III, which are associated with the greatest risk of SCI. ${ }^{2}$ The 67 TAAAs in this series were distributed according to Crawford extent as follows: extent I (26\%), extent II $(25 \%)$, extent III $(9 \%)$, extent IV $(3 \%)$, and extent V $(4 \%)$. Comparing the DTA and TAAA results reflected the significant differences in the risks associated with each. The 30-day mortality rate was 3\% in the DTA group compared with $10 \%$ in the TAAA group. Similarly, the paraplegia rate was zero in the DTA group and 3\% (2/67) in the TAAA group.

To put this in a broader context, in a recent systematic review and meta-analysis by Gaudino and colleagues ${ }^{4}$ of 169 studies and 22,634 patients, the overall incidence of SCI was $4.9 \%$ for open DTA repairs and $7.0 \%$ for open TAAA repairs. The incidence of SCI varied substantially by TAAA extent: extent I ( $4 \%$ incidence of SCI), II $(15 \%)$, III (7\%), IV (2\%), and V (7\%). A more nuanced comparison would further take into account the mean age of the patients, the proportion presenting with rupture or requiring urgent or emergency surgery, and the proportion 
presenting with chronic symptoms, because all of these factors are associated with increasing SCI risk. ${ }^{5}$

It is important to maintain a sense of humility when reporting good results, as the Yale group has demonstrated when it comes to SCI and TAAA repairs. In our own experience, we have had 4 separate periods during which we performed more than 100 consecutive TAAA repairs $(102,113$, 117 , and 261) without any permanent paraplegia and another 11 similar periods during which we performed more than 50 consecutive repairs without paraplegia (JS Coselli, unpublished data, 2020). Thus, there is real value to either a large, single-center series or the aggregation of results from a meta-analysis. In Gaudino and colleagues' systematic review, it should be noted that $52(31 \%)$ of the studies included more than 100 patients, $8(5 \%)$ studies had more than 500 patients, and $2(1 \%)$ had more than 1000 patients. ${ }^{4}$

The Yale group used a variety of strategies in addition to $100 \%$ CSFD, including left atrial-femoral arterial bypass (96\% of cases), preserving intercostal arteries (72\%), monitoring motor-evoked potentials $(67 \%)$, and preoperative detection of the anterior spinal artery $(67 \%)$. Although we do not routinely use motor- or somatosensory-evoked potentials, we acknowledge that other surgical groups do so with good outcomes.

These results reflect surgical expertise and a variety of preoperative and intraoperative adjuncts, highlighting brilliantly the maxim put forth by British cycling coach David Brailsford of "aggregation of marginal gains," whereby meaningful and noticeable process improvement can result from improvements of as little as $1 \%$ across several areas. Thus, several different specific measures can add up to a meaningful reduction in SCI.

The role of CSF drainage in TAAA repair was highlighted in a 2012 Cochrane review of 3 randomized trials that included a total of 287 patients, thereby establishing its role in TAAA repair. ${ }^{6}$ Although the conclusion was that CSFD demonstrated "limited data" in DTA/TAAA, the largest of these trials $\left(n=145^{7}\right)$ showed an $80 \%$ relative risk reduction (12.2\% incidence of $\mathrm{SCI}$ in the control group vs $2.7 \%$ in the CSFD group, $P=.03$ ) in extent I and II TAAA repairs, which led to CSFD recommendations in both the American $\left(\right.$ Class IB $^{8}$ ) and European (Class IIA ${ }^{9}$ ) guidelines.

Abdelbaky and colleagues' report is further enhanced by providing real-world guidance on a variety of specific perioperative management considerations familiar to all for whom CSFD is part of their routine practice. ${ }^{10}$ While the primary focus with CSFD is rightly first on preventing SCI complications, the authors also discuss complications associated with CSFD itself_-such as a "bloody tap," spinal headaches, and the use of blood patches-and perioperative management, as detailed by other centers with large experiences. ${ }^{11,12}$ The authors' $14 \%$ rate of CSFD complications (which were mostly minor: $9 \%$ blood-tinged CSF, $1 \%$ subdural hematoma) compares favorably with the results of 2 distinct metanalyses that showed an $8 \%$ to $13 \%$ incidence of complications of variable severity. 4,13

Standardized surgical techniques and diligent perioperative management with CSFD for TAAA repair can lead to very good surgical outcomes, as Abdelbaky and colleagues demonstrate. These lessons should remain in our practice and inspire the next "marginal gain" toward better spinal cord protection.

\section{References}

1. Svensson LG, Crawford ES, Hess KR, Coselli JS, Safi HJ. Experience with 1509 patients undergoing thoracoabdominal aortic operations. J Vasc Surg. 1993;17: 357-68; discussion 68-70.

2. Coselli JS, LeMaire SA, Preventza O, de la Cruz KI, Cooley DA, Price MD, et al. Outcomes of 3309 thoracoabdominal aortic aneurysm repairs. J Thorac Cardiovasc Surg. 2016;151:1323-37.

3. Abdelbaky M, Papanikolaou D, Zafar MA, Ellauzi H, Shaikh M, Ziganshin BA, et al. Safety of perioperative cerebrospinal fluid drain as a protective strategy during descending and thoracoabdominal open aortic repair. J Thorac Cardiovasc Surg Tech. 2021;6:1-8.

4. Gaudino M, Khan FM, Rahouma M, Naik A, Hameed I, Spadaccio C, et al. Spinal cord injury after open and endovascular repair of descending thoracic and thoracoabdominal aortic aneurysms: a meta-analysis. J Thorac Cardiovasc Surg. May 13, 2020 [Epub ahead of print].

5. Coselli JS, Green SY, Price MD, Zhang Q, Preventza O, de la Cruz KI, et al. Spinal cord deficit after 1114 extent II open thoracoabdominal aortic aneurysm repairs. J Thorac Cardiovasc Surg. February 19, 2020 [Epub ahead of print].

6. Khan SN, Stansby G. Cerebrospinal fluid drainage for thoracic and thoracoabdominal aortic aneurysm surgery. Cochrane Database Syst Rev. 2012;10: CD003635.

7. Coselli JS, LeMaire SA, Koksoy C, Schmittling ZC, Curling PE. Cerebrospinal fluid drainage reduces paraplegia after thoracoabdominal aortic aneurysm repair: results of a randomized clinical trial. J Vasc Surg. 2002;35:631-9.

8. Hiratzka LF, Bakris GL, Beckman JA, Bersin RM, Carr VF, Casey DE Jr, et al. 2010 ACCF/AHA/AATS/ACR/ASA/SCA/SCAI/SIR/STS/SVM guidelines for the diagnosis and management of patients with thoracic aortic disease. A report of the American College of Cardiology Foundation/American Heart Association Task Force on Practice Guidelines, American Association for Thoracic Surgery, American College of Radiology, American Stroke Association, Society of Cardiovascular Anesthesiologists, Society for Cardiovascular Angiography and Interventions, Society of Interventional Radiology, Society of Thoracic Surgeons, and Society for Vascular Medicine. J Am Coll Cardiol. 2010;55: e27-129.

9. Erbel R, Aboyans V, Boileau C, Bossone E, Bartolomeo RD, Eggebrecht H, et al. 2014 ESC guidelines on the diagnosis and treatment of aortic diseases: document covering acute and chronic aortic diseases of the thoracic and abdominal aorta of the adult. The Task Force for the Diagnosis and Treatment of Aortic Diseases of the European Society of Cardiology (ESC). Eur Heart J. 2014;35:2873-926.

10. Chatterjee S, Casar JG, LeMaire SA, Preventza O, Coselli JS. Perioperative care after thoracoabdominal aortic aneurysm repair: the Baylor College of Medicine experience. Part 2: postoperative management. J Thorac Cardiovasc Surg. 2021; 161:699-705.

11. Estrera AL, Sheinbaum R, Miller CC, Azizzadeh A, Walkes JC, Lee TY, et al. Cerebrospinal fluid drainage during thoracic aortic repair: safety and current management. Ann Thorac Surg. 2009;88:9-15; discussion 15.

12. Youngblood SC, Tolpin DA, LeMaire SA, Coselli JS, Lee VV, Cooper JR Jr. Complications of cerebrospinal fluid drainage after thoracic aortic surgery: a review of 504 patients over 5 years. J Thorac Cardiovasc Surg. 2013;146: 166-71.

13. Rong LQ, Kamel MK, Rahouma M, White RS, Lichtman AD, Pryor KO, et al. Cerebrospinal-fluid drain-related complications in patients undergoing open and endovascular repairs of thoracic and thoraco-abdominal aortic pathologies: a systematic review and meta-analysis. Br J Anaesth. 2018;120:904-13. 